\title{
DAÑOS Y EFECTOS DEL FUEGO SOBRE VEGETACIÓN NATIVA EN PAISAJES COSTEROS DE CHILE CENTRAL ESTUDIO DE CASO: LA PALMA CHILENA*
}

\author{
Miguel Castillo Soto \\ Laboratorio de Incendios Forestales \\ Universidad de Chile \\ migcasti@uchile.cl
}

\begin{abstract}
Resumen: Se analiza el estado actual de poblaciones adultas de Jubaea chilensis Mol. Baillon, presentes en cerros y quebradas del colinaje costero de la Quinta Región. Mediante la utilización de imágenes satelitales Landsat correspondientes a cinco períodos de fuegos, con el apoyo de imágenes aéreas de alta resolución, y campañas de terreno en un período de 21 meses de seguimiento, se caracterizaron ejemplares adultos de palma chilena en laderas de exposiciones Norte y Este, en transectos altitudinales. Los resultados indican que la distribución poblacional se concentra en un estado adulto con fase de desmoronamiento, y en un proceso acelerado y regresivo de degradación, con escasas posibilidades de regeneración natural producto de la alta frecuencia e intensidad de incendios. El proceso de fragmentación del paisaje vegetal, favorecido por procesos antrópicos derivados de la construcción de caminos, los incendios, extracción de leña y aumento de poblados en sectores de cerros cercanos a la vegetación circundante, acentúa este problema, el cual no muestra señales de revertir.
\end{abstract}

Palabras clave: Incendio Forestal, Paisaje, Palma chilena.

Abstract: The current state of adult of Jubaea chilensis Mol. Baillon present in hills and gorges of costal area of the fifth Region is analyzed. By means of the use of Landsat satellite images corresponding to five periods of fires, with the support of aerial images of high resolution, and field campaigns in a period of 21 months of pursuit, adult units of Palma Chilena in north and east mountainside were characterized, in altitude transect. The results indicate that the population distribution is concentrated in an adult state with phase of decline, and in a process acceler-

* Recibido: 23-03-10. Aceptado: 10-02-11. 
ated and regressive of degradation, with little possibilities of natural regeneration product of the high frequency and intensity of fires. The process of fragmentation of the vegetal landscape, favored by anthropic processes derived from the road construction, fires, extraction of firewood and increase of towns in hill sectors near the surrounding vegetation, accentuates this problem, which does not show signals to revert.

Keywords: Forest Fire, Landscape, Palma chilena.

\section{Introducción}

El cambio del paisaje vegetal producto de la acción del fuego, forma parte de los ecosistemas mediterráneos de muchas partes del mundo. El efecto de este agente modificador ha sido estudiado en diversas especies vegetales de alto valor endémico. Estudios clásicos de este tipo de fenómenos han sido estudiados por Chadwick y Bruce (1997) en dinámica de bosques naturales, y el cambio en el paisaje afectados por reiterados incendios (Fulé e. al., 2003; Fuller, 2001).

En el caso de Sudamérica, existen especies de alto valor geobotánica que coexisten con el cambio de uso del suelo producto de la expansión de territorios para urbanización. De allí que este estudio adquiere importancia porque intenta ilustrar los efectos producidos por la actividad humana (reflejada en incendios) como un factor de presión sobre poblaciones fragmentadas de esta valiosa especie.

Jubaea chilensis Mol. Baillon, es la palma más austral del mundo y, por lo tanto, una de las especies de mayor valor científico de la flora nativa de Chile, constituyéndose en uno de los referentes de mayor interés para la caracterización de la vegetación mediterránea costera de la Quinta Región. El aumento de la población humana desde el siglo XIX, la modificación del medio ambiente y el tradicional manejo que se le ha dado a la palma chilena en los ambientes que habita, han ocasionado una disminución progresiva de su población. Actualmente esta especie se encuentra clasificada por la Corporación Nacional Forestal (CONAF), en la Categoría de Especie Vulnerable.

Su distribución original está en discusión, pero se establece por varios autores su límite sur en el Río Maule y el límite norte en el Río Limarí. Su rango de altitud va desde los 400 a los 1400 m.s.n.m. La distribución latitudinal sugiere una asociación a las vertientes occidentales de la Cordillera de la Costa, con incursiones en el valle longitudinal. En la actualidad, su área de distribución está reducida a algunos ejemplares de valles y quebradas, siendo las agrupaciones más numerosas las ubicadas en el valle de Ocoa (62.000 ejemplares), la cuenca de Cocalán (35.000 
ejemplares) y El Salto (6.500 ejemplares). Es una especie productiva de uso histórico, de la cual se pueden obtener sus frutos, miel y hojas, lo cual la ha llevado a una explotación excesiva.

De acuerdo a los antecedentes existentes hasta mediados de los años 80, esta especie se encontraba en un franco peligro de extinción, producto de la explotación indiscriminada para la producción de miel de palma, la cosecha de semillas para el consumo humano, la extracción de hojas en temporadas de fiestas religiosas, y la acción reiterada del fuego en períodos de verano (González, 1998). Es así que las quebradas aledañas al camino de acceso a Valparaíso y Viña del Mar, presentaban cada vez menos ejemplares de esta especie, como consecuencia de la disminución ocasionada por efectos de la presión humana existente en dicha área. El crecimiento de poblaciones aledañas manifestado en la construcción de viviendas ligeras en sectores colindantes a quebradas pobladas de vegetación y basurales, generó por años problemas de degradación de la palma y los consecuentes incendios producto de la actividad de pobladores confinados a estos sectores.

Como consecuencia de lo anterior, actualmente es posible identificar claramente aquellos sectores que presentan testimonios claros de degradación de la palma. Un ejemplo importante es lo ocurrido en el Palmar existente en la Hacienda Las Siete Hermanas, situado al sureste de la ciudad de Viña del Mar. En efecto, la cercanía que presentan los suburbios de esta ciudad a los terrenos que conforman la Hacienda, son una clara señal de la presión que se ejerce sobre todos los recursos existentes y que se circunscriben básicamente a las poblaciones de palma chilena presentes en el área. Otro factor que ha sido altamente relevante en la degradación de esta especie ha sido la destrucción de cerros para la construcción de carreteras, en donde justamente se presentan importantes poblaciones de ejemplares adultos de palma.

El primer rasgo que permite caracterizar esta alteración se evidencia en la composición de la vegetación misma. El colinaje costero y quebradas interiores, constituido históricamente por formaciones densas de bosque esclerófilo, entremezclado con palmares, ha derivado a estadios dominantes por un matorral semidenso a ralo, altamente intervenido, y en donde se encuentran presentes renuevos del antiguo bosque. La explotación del bosque para la sustracción de leña y la actividad de la caza, son los factores responsables más comunes que iniciaron la degradación de estos ambientes.

Si se considera además la actividad de los pobladores en la búsqueda de ramas para implementar arreglos florales, el carboneo, recolección de frutos, particularmente de palmas y en mayor grado los incendios, es posible entonces encontrar transformaciones muy importantes en la estructura y composición de las agrupaciones vegetales. 
Este fenómeno ha tenido importantes repercusiones también en las áreas periféricas a las quebradas y cuencas, particularmente en el trabajo con maquinarias para la remoción de grandes volúmenes de tierra para habilitación de nuevos terrenos para la construcción, o en la planificación de nuevas pistas, tal como ocurrió entre los años 1994 a 1997 con la construcción de una carretera de dos pistas que pasa por la periferia de Viña del Mar para conectarse con las localidades de Concón-Quintero por el norte y con Santiago por el sur. El trazado final provocó profundas transformaciones en ecosistemas de colinas costeras. Se eliminó y alteró centenares de hectáreas de bosque esclerófilo, depositándose a su vez toneladas de tierra en el fondo de algunas quebradas (Quintanilla, 1998). Otro grave impacto provocado por esta obra denominada vía o carretera Las Palmas, fue la destrucción y remoción de numerosas palmas presentes en el lugar. Los efectos sobre la estabilidad del suelo y los cambios visuales en el paisaje fueron tan evidentes, que hubo la necesidad de adoptar medidas para restaurar con mallas especiales y especies vegetales en algunos taludes a orilla de carretera que presentaban serio peligro para el tráfico vehicular.

Otro daño severo a la continuidad de los parches de palma chilena y en general del paisaje vegetal, fue la habilitación y despeje de extensas fajas de terreno cubiertas de vegetación para la instalación cañerías destinadas al transporte de gas por la empresa Gas Andes a la ciudad de Viña del Mar. El trazado, de aproximadamente 21 kilómetros de longitud, atraviesa múltiples cuencas y laderas con la consiguiente remoción de materiales y la interrupción espacial de ambientes naturales mediante la inserción de parches artificiales al paisaje natural con un evidente aumento del efecto de borde. Las medidas de mitigación y restauración no fueron suficientes para aminorar este efecto en los sectores intervenidos, evidenciándose actualmente una claro deterioro en las áreas aledañas al trazado, manifestado en una mayor erosión de las cuencas y en la mayor probabilidad de tumbado de palmas y ocurrencia de incendios producto de la exposición de parches naturales frente a zonas desprovistas de vegetación y nuevos senderos para el tránsito de personas.

\section{Materiales y Métodos}

Siguiendo la metodología propuesta por Gergel y Turner (2002) y Cardille et. al. (2001), se trabajó a dos escalas geográficas, intentando relacionar estas modificaciones con el entorno del área de estudio.

El área de estudio correspondió al frente principal de avance de un incendio ocurrido en el mes de febrero de 2004, cuyo foco se localizó en el Fundo Las Cenizas (Comuna de Valparaíso). El avance del fuego tuvo como consecuencia una rápida propagación hacia el norte, abarcando microcuencas del Fundo Siete Hermanas, al sur de la Población Puerto Montt, en la Comuna de Viña del Mar (figura 1). 


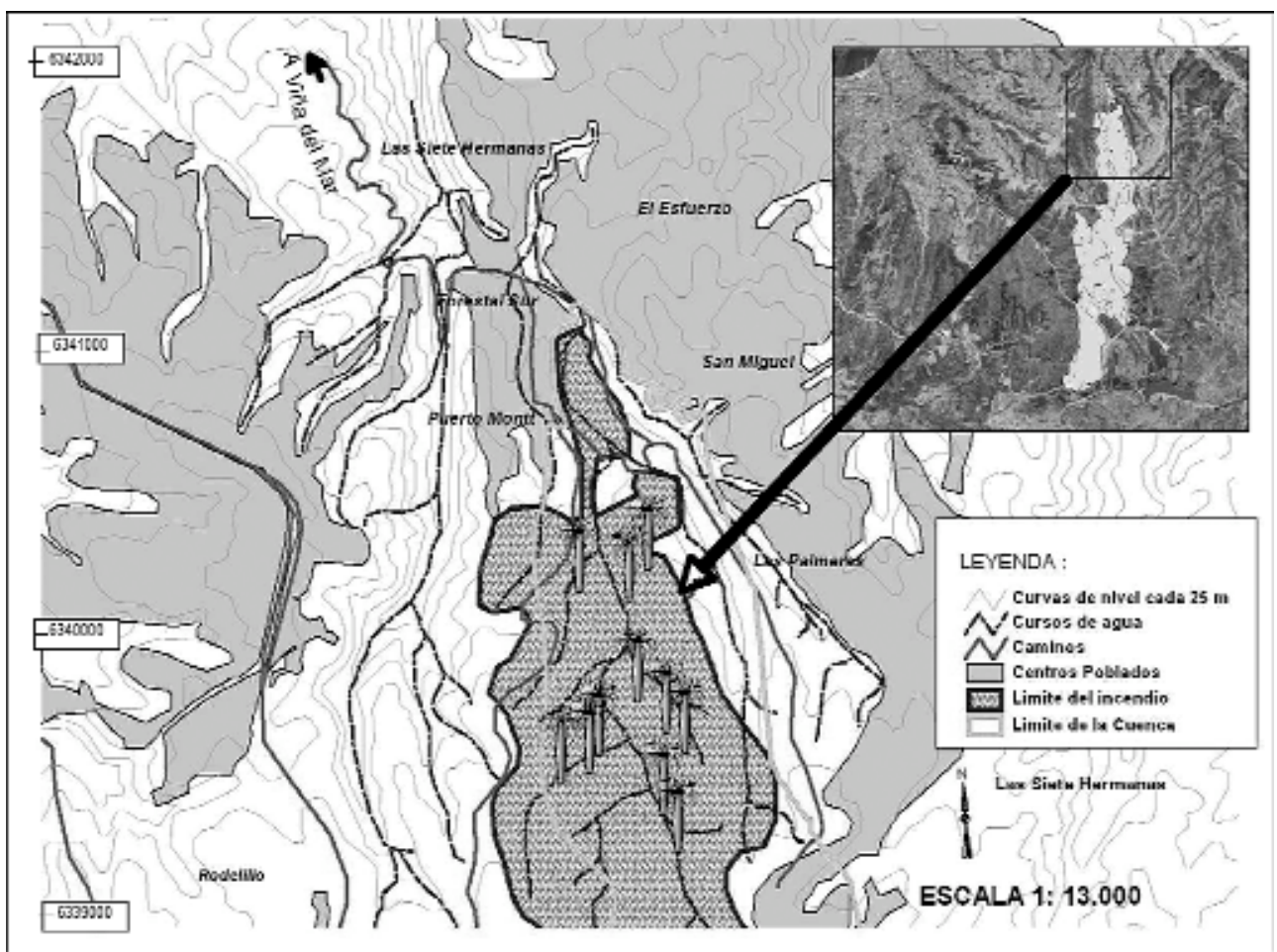

Figura 1. Área de estudio: sección norte de un incendio que afectó a 570 hectáreas entre palmares, matorrales, pastizales, arbolado nativo y plantaciones. El área quemada fue cartografiada mediante la observación, trabajo de campo y posterior digitalización a base de fotografías aéreas de los cerros afectados y luego corregidos en función de la pendiente.

En el área antes señalada se establecieron transectos lineales para analizar la vegetación afectada por el fuego. En cada uno de ellos se elaboró un censo fitosociológico considerando la metodología utilizada por Quintanilla (1998), para la caracterización de la vegetación en muestras de terreno. Por lo anterior, la toma de datos se organizó en 24 censos de vegetación (tabla 1), consistentes en cuatro parcelas de $40 \mathrm{~m}^{2}$ distribuidas en exposiciones Norte, Sur, Este y Oeste; y en tres secciones de pendientes para cada perfil de ladera (sección alta, media y fondo), y para los estratos arbóreo y arbustivo ( 2 estratos). Esta actividad se realizó en un lapso total de 21 meses de seguimiento de la vegetación post fuego (febrero 2004 noviembre 2005).

Para una caracterización en detalle de los daños ocasionados por el fuego al incendio en estudio, se acotó el sector local a las laderas con mayor presencia de 


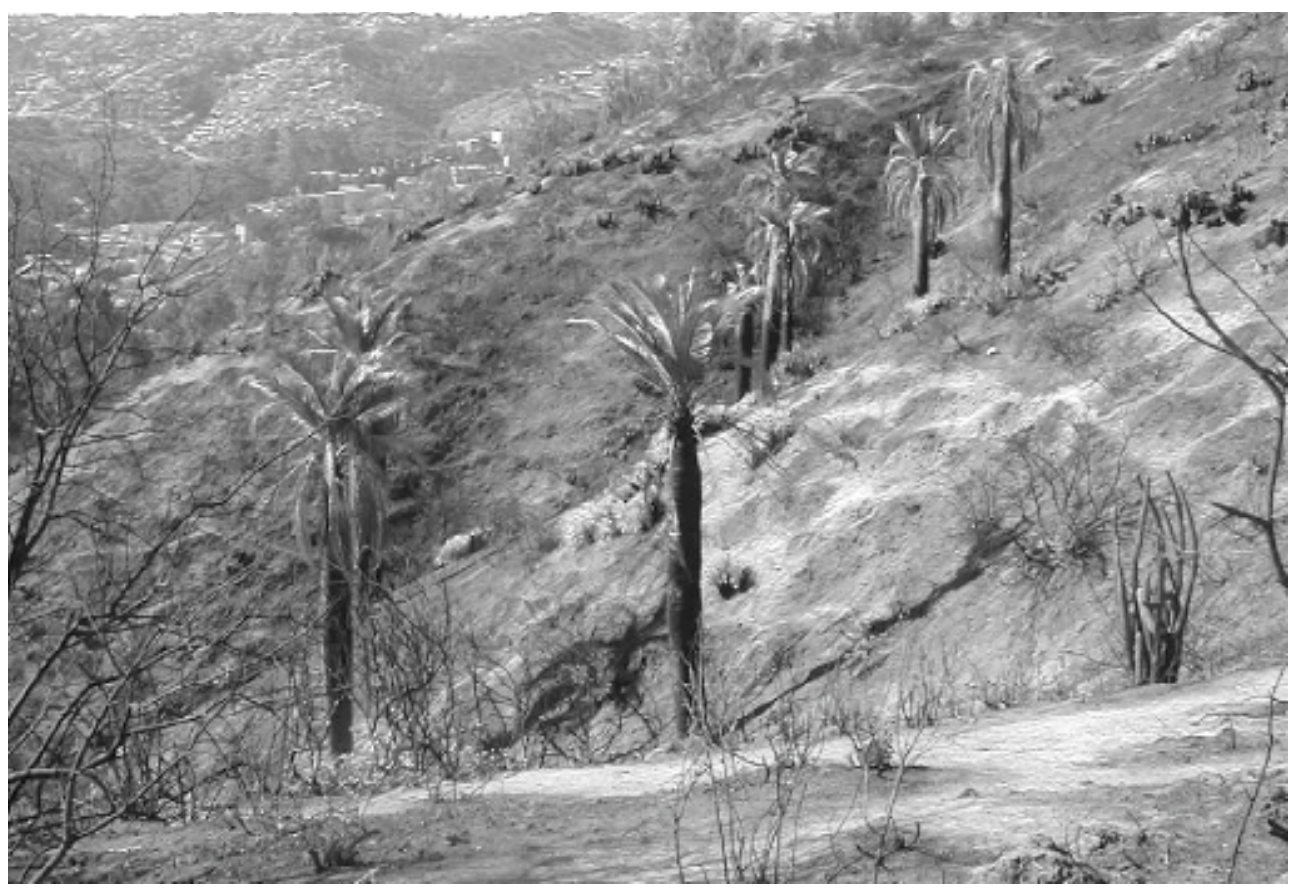

Figura 2. Detalle del área de estudio, localizada en el sector sur de Viña del Mar.

vegetación quemada, considerando además la presencia de laderas testigo. El área de estudio corresponde a la sección oeste de la cabeza del incendio, confinada entre quebradas de pendientes moderadas a fuertes. En la periferia, coexisten sectores de basurales y lugares de deposición de materiales de construcción y residuos domésticos. El lugar presenta accesos interiores para actividades de extracción de leña, y laderas de alta pendiente donde aún es posible observar ejemplares de palma chilena en estado adulto. Las quebradas aledañas muestran un evidente estado de deterioro de la vegetación, recurrentemente afectada por incendios. Corresponde a un área colindante a centros poblados en donde la expansión progresiva de las ciudades de Valparaíso y Viña del Mar, se ha manifestado en la construcción de numerosas viviendas ligeras, muchas veces carentes de servicios básicos, y que han provocado el deterioro de las quebradas aledañas.

Se eligen estos sectores en particular, dado que es posible identificar todas las variantes de exposición en laderas, con predominancias en sectores Este y Oeste, y grados de pendiente moderados a fuertes, hasta el fondo de quebradas. En general se observa un matorral leñoso completamente degradado por el fuego, con sectores testigo compuesto por gramíneas, matorral esclerófilo y escasos remanentes de 
bosque confinados en sectores más protegidos. Se aprecia en general, el vigor de la regeneración sobre las cenizas, conformándose un primer paño vegetal compuesto de pequeñas plántulas y gramíneas, junto a una abundante regeneración de matorral esclerófilo, a tres meses después de la acción del fuego. En sectores de fondo de quebrada, se aprecia un estado mayor de abrigo de la vegetación remanente, aunque sujeta a una intensa presión antrópica, principalmente por la extracción de leña residual.

Para una caracterización general de las áreas quemadas, y con presencia de palma chilena, se utilizaron imágenes satelitales Landsat TM de cinco temporadas de fuegos (años 1986, 1989, 1995, 1999 y 2003), más fotografías aéreas digitales tomadas en 2001 y 2004. Las imágenes del sensor Landsat permitieron establecer los patrones generales de recurrencia de fuegos, que en conjunto con las fotos aéreas de alta resolución, y el incendio forestal ocurrido en el mes de febrero de 2004, permitieron focalizar aquellos sectores con existencia de ejemplares adultos de palma.

En forma adicional, se consideró la inclusión de una base de datos de ocurrencia y causas de incendios forestales que afectaron principalmente a vegetación nativa en los últimos 20 años, la cual sirvió de apoyo para identificar las áreas afectadas por el fuego.

En estos sectores, se establecieron cinco campañas de terreno para la caracterización de laderas quemadas, en transectos lineales (figura 3), dispuestos en orientaciones Norte y Este, dado que en ellos se detectaron importantes agrupaciones de ejemplares adultos de palma.

Respecto a los niveles de intensidad del fuego, éstos fueron evaluados descriptivamente en terreno, considerando las referencias generales procedentes de SEVEIF (2010), para áreas quemadas en este tipo de ecosistemas para la Región Central de Chile.

\section{Resultados}

A escala local, el área norte del estudio (sector sur de Hacienda Siete Hermanas) ha sido afectada en 9 ocasiones por incendios superiores a 10 hectáreas, y en 37 ocasiones por incendios menores a esa superficie. El siniestro analizado ha sido uno de los más importantes dentro de la serie histórica, no sólo por la superficie afectada, sino por el valor botánico comprometido.

Actualmente la palma continúa soportando los efectos del crecimiento urbano. Los reiterados fuegos y el consecuente daño a las especies vegetales acompañantes y al 
suelo, generan condiciones propicias para la caída de ejemplares adultos producto de la inestabilidad del suelo quemado. Este efecto pudo verse en forma particular y notable, en laderas de exposiciones Norte y Este del sector en estudio, dado que en estas áreas existe una mayor conectividad con accesos a personas que extraen material vegetal y que ocasionan incendios.

En laderas de exposición Este, fue posible apreciar que la estructura y composición de especies ha estado caracterizada por la presencia de leñosas mayores, entre ellas la palma. Las altas pendientes evidenciadas (sobre 60\%), indican un alto grado de daño al suelo en prácticamente todo el perfil, encontrándose sectores completamente desprovistos de vegetación (figura 3).

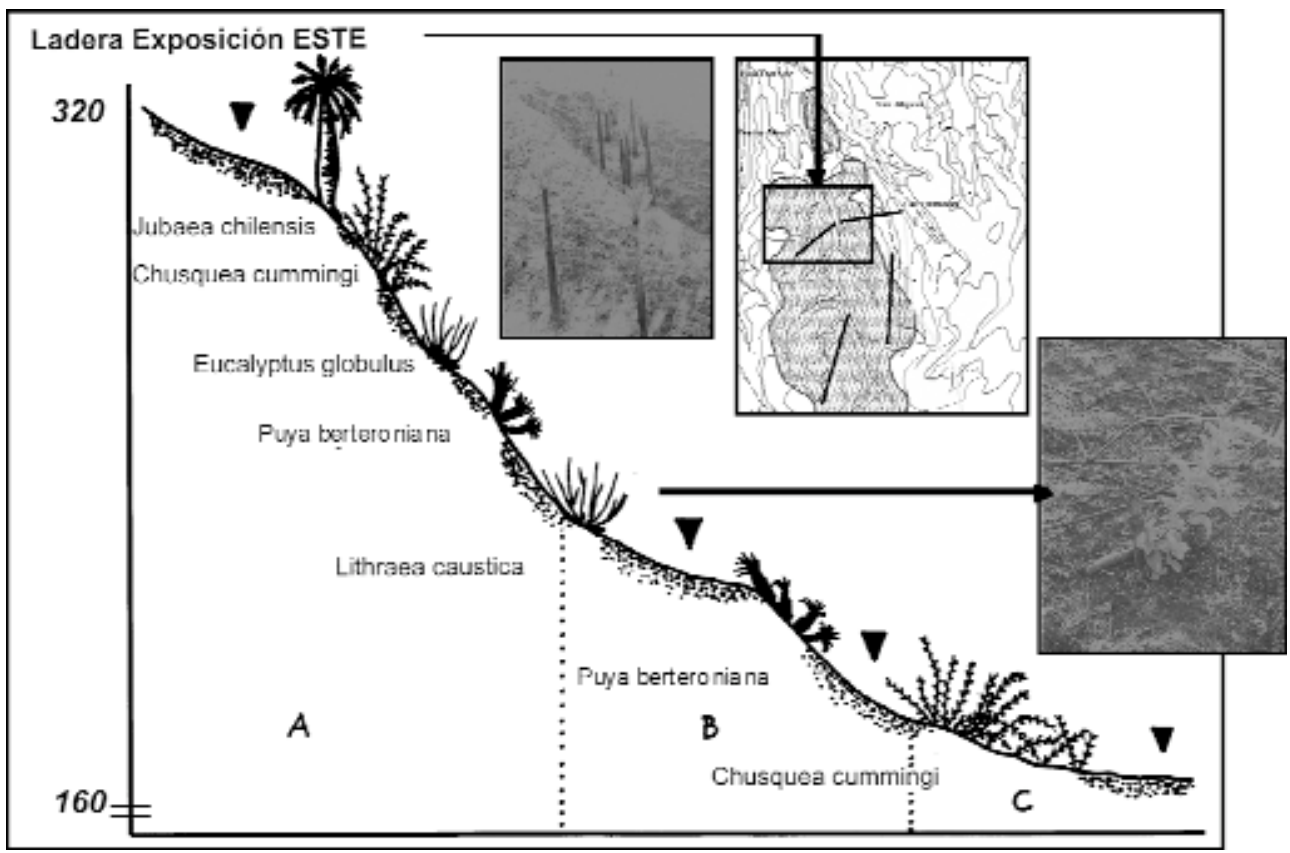

Figura 3. Diagrama de la vegetación afectada por el fuego en ladera de exposición este. Cerros sector sur Población Puerto Montt. Situación tres meses post-fuego. Ladera de Exposición este. Vegetación quemada: $100 \%$ de daño. Regeneración escasa a nula en todo el perfil. Porcentajes de cobertura de leñosas quemadas: $5-10 \%$ en sector $A ; 10 \%$ en sector $B, 30 \%$ en sector $C$. $\mathbf{\nabla}$ : espacios quemados sin remanentes de vegetación (suelo hecho cenizas). Pendientes entre 50 a $100 \%$. Más fuertes en sector A del perfil. 


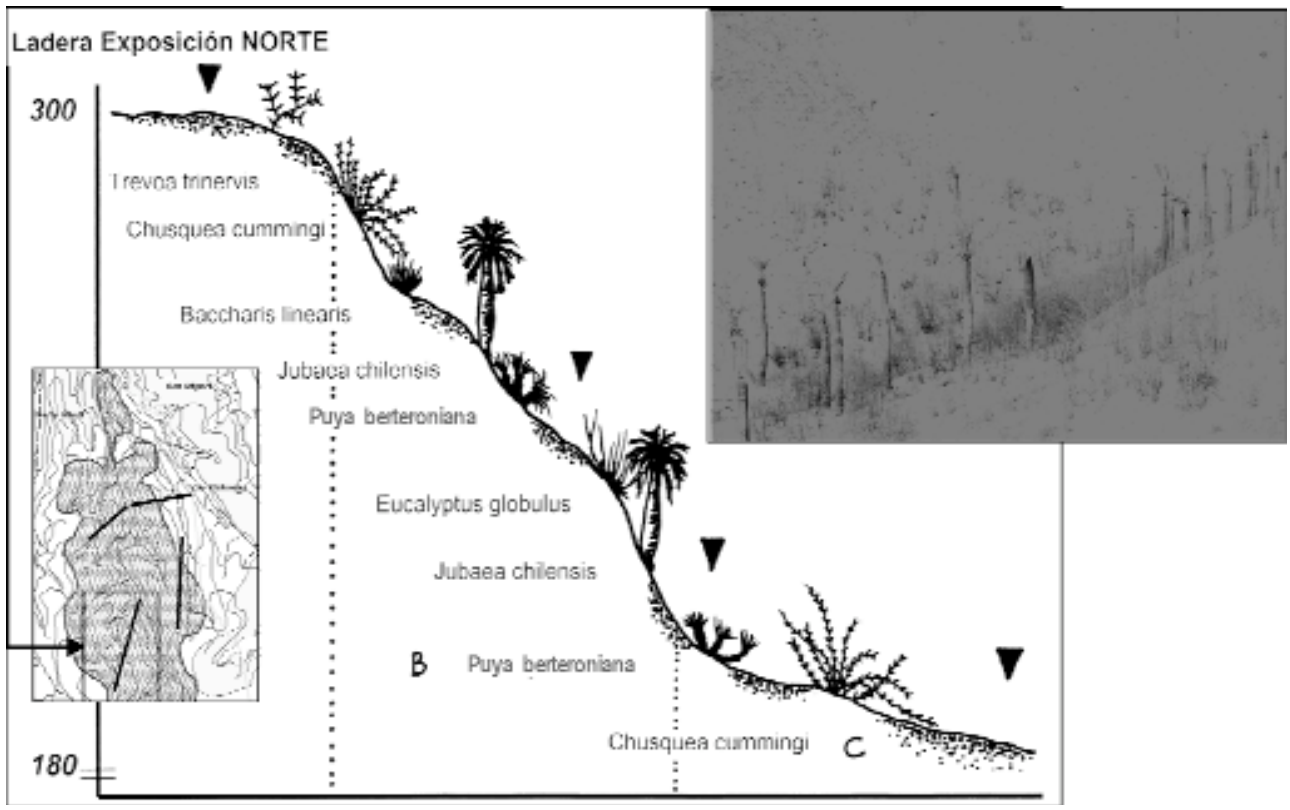

Figura 4. Cerros sector sur Población Puerto Montt. Situación tres meses post-fuego. Ladera de Exposición Norte Vegetación quemada: $100 \%$ de daño. Regeneración escasa a nula en todo el perfil. Porcentajes de cobertura de leñosas quemadas: $5-10 \%$ en sector $A ; 5 \%$ en sector $B, 10 \%$ en sector $C$. $\mathbf{\nabla}$ : espacios quemados sin remanentes de vegetación (suelo hecho cenizas). Pendientes entre 30 a $70 \%$. Más fuertes en sector B del perfil.

Tres meses después de la acción del fuego es posible observar un acelerado proceso de regeneración especialmente en rebrotes de colihue, gramínea que demuestra una elevada capacidad de recuperación frente al fuego. Las especies acompañantes en el transecto evidencian daño total. A su vez, el suelo muestra los efectos de la desestabilización al crearse cavidades donde antes había material vegetal vivo.

En ladera de exposición norte (Figura 4) el efecto del fuego es severo en prácticamente todo el perfil. En el sector B del transecto es posible identificar importantes daños al suelo y a los palmares que allí se encuentran. En la parte alta se encuentra el trevo, junto a colihue con $100 \%$ de daño, y con escasa a nula evidencia de regeneración en lo referente a plantas acompañantes. El sector A presenta sin embargo, una estabilidad mecánica del suelo aceptable, a un 5\% de recubrimiento vegetal. Pendiente abajo el grado de recubrimiento de materiales vivos y quemados aumenta. El matorral esclerófilo existente presentaba evidentes signos de 


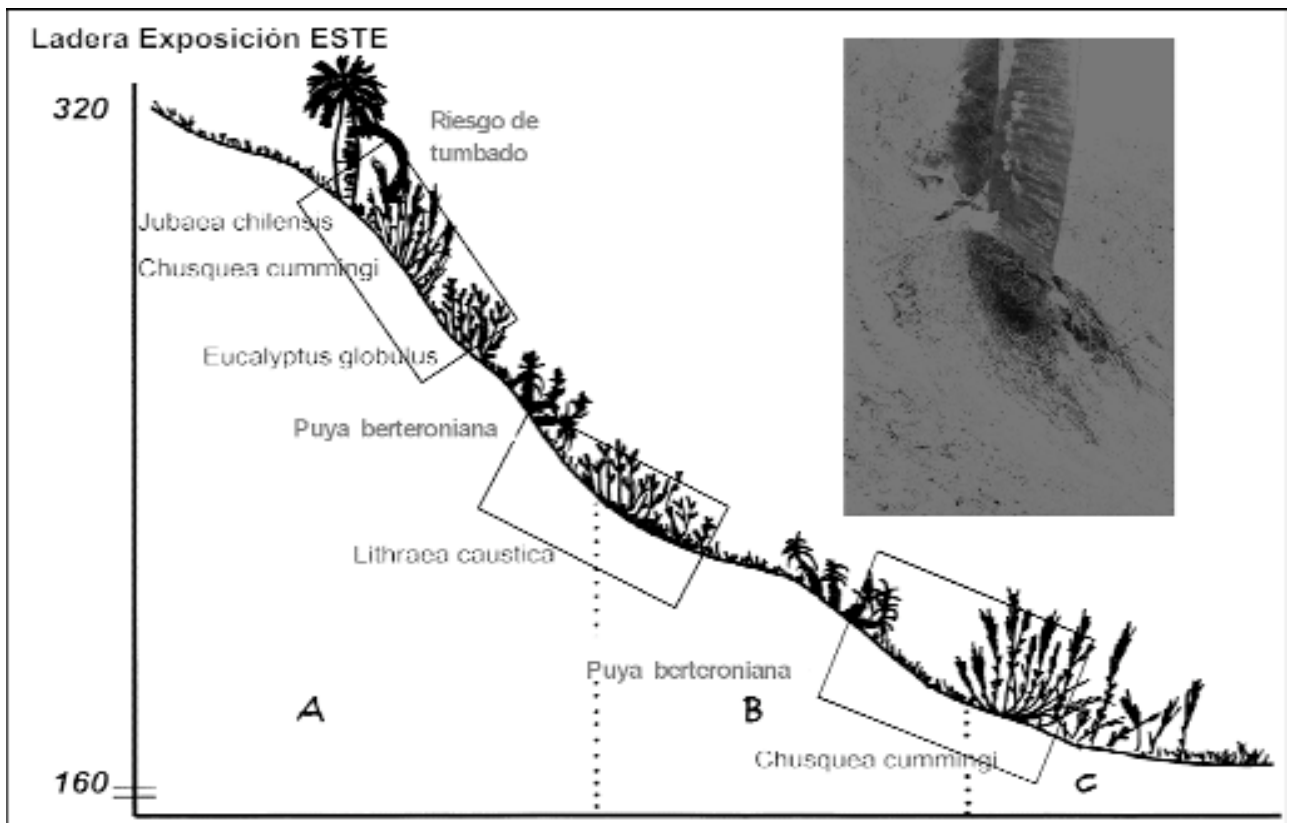

Figura 5. Sector sur Población Puerto Montt. Situación seis meses post-fuego. Ladera de Exposición Este. Regeneración moderada, concentrada en las partes bajas del perfil. Los recuadros señalan las áreas con mayor actividad de repoblamiento y regeneración.

degradación antes del incendio, por lo cual la sucesión florística lleva a la presencia de algunas leñosas típicas del matorral degradado, entre ellas el romerillo.

A seis meses de la acción del fuego, y en laderas de exposición Este, los daños más importantes se concentran en las palmas, cuya estabilidad se ve seriamente afectada producto de la desestabilización del suelo. A seis meses del fuego y, aunque la regeneración de la vegetación menor en todo el perfil es abundante, se advierte un acelerado proceso de socavamiento del suelo en las partes bajas de los fustes de palma, ocasionando la rápida pérdida de material fino y piedras que ruedan hacia las partes bajas del perfil.

A su vez, en laderas de exposición norte, el recubrimiento se manifiesta con mayor fuerza en el sector A del transecto, y hasta aproximadamente los $200 \mathrm{~m}$ ladera abajo (figura 6). 


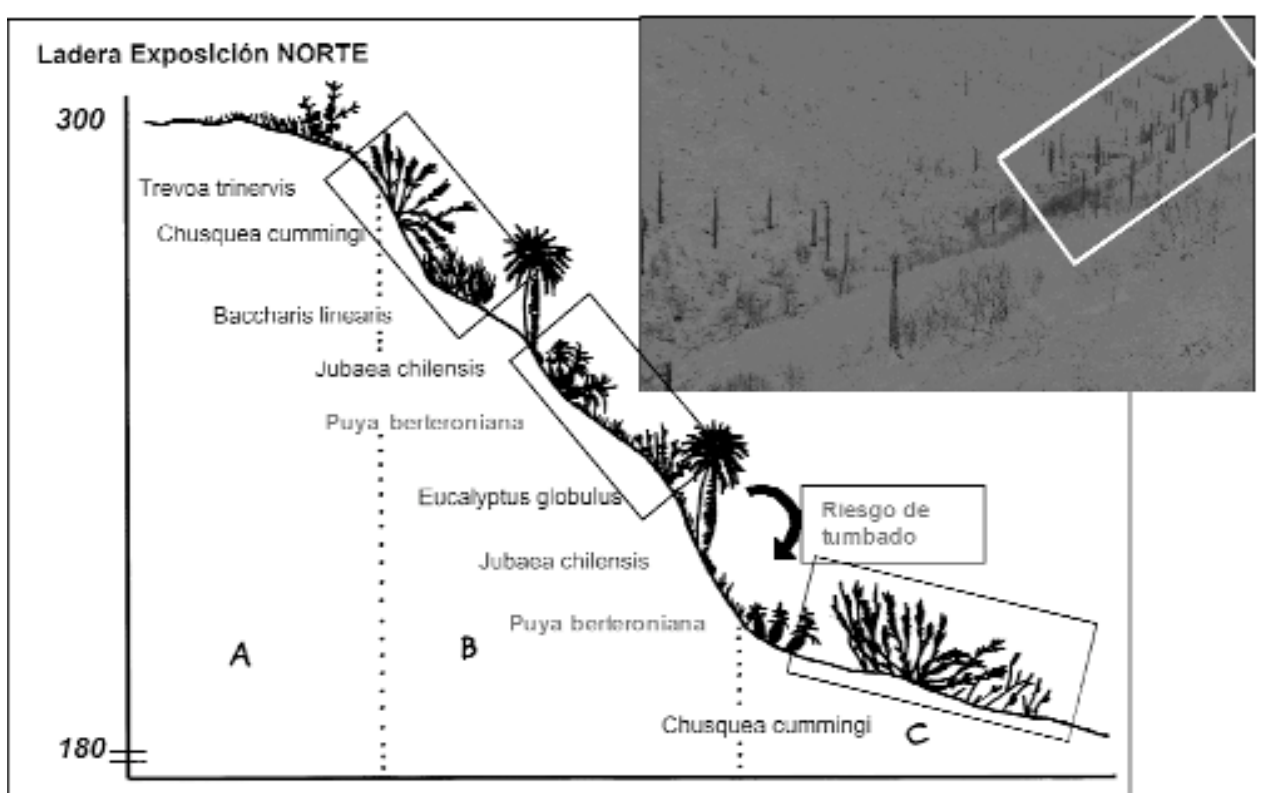

Figura 6. Cerros sector sur Población Puerto Montt. Situación seis meses post-fuego. Ladera de Exposición norte. Regeneración vigorosa en todo el perfil. Los espacios quemados comienzan a ser repoblados por herbáceas y retoños de tocón. Los recuadros señalan las zonas con mayor actividad de repoblamiento y regeneración.

\section{Discusión}

A seis meses de la acción del fuego ya es posible ver importantes cambios en el recubrimiento de las laderas. Sin embargo, y como puede apreciarse en la tabla 2, los recubrimientos son más vigorosos en la vegetación invasora y para prácticamente todas las condiciones fisiográficas estudiadas. A excepción de los renuevos de litre y quillay, los rápidos recubrimientos quedan reflejados en el repoblamiento de gramíneas menores y en el rebrote vigoroso de colihue. A la fecha de esta segunda visita (20 de agosto de 2004), el agua caída medida por la estación meteorológica que cubre el sector de estudio era de 365,1 mm acumulados desde el 1 de enero de 2004, y de $91 \mathrm{~mm}$ en los últimos 20 días.

En esta tabla, se detalla que las especies del estrato arbustivo reaparecen vigorosamente, conformando un manto vegetal en dos estratos: una densa capa de colihue entremezclada con renuevos del estrato arbóreo degradado compuesto por litre, quillay y chagual, con alturas de rebrotes que varían entre 0.2 y $1.8 \mathrm{~m}$, a seis 
meses del fuego. Estos antecedentes respaldan a lo estudiado por Daigle (1996) en cuanto a que los reiterados incendios sobre una misma área (en este caso, sobre los 60 eventos en 20 años), hacen que la capacidad de rebrote natural de las especies nativas se vea paulatinamente disminuida por la competencia en luz, espacio y nutrientes con especies invasoras, las cuales pasan en muchos casos a formar estados consolidados de matorral degradado.

Las cifras indicadas en la tabla 2, para el estrato herbáceo y arbustivo, señalan una importante actividad regenerativa, comparativamente mayor a la respuesta de las especies del estrato arbóreo. Es destacable el rápido recubrimiento de espacios abiertos con matorral arbustivo en un suelo con sectores completamente descubiertos por la acción de las precipitaciones acumuladas hasta mediados del mes de agosto. La liberación de semillas y la reactivación de propágalos de especies del matorral esclerófilo, comenzaron a dar signos de recuperación, manifestado en la ocupación de laderas completamente expuestas a la acción de las lluvias.

En las parcelas de terreno analizadas es posible identificar en líneas generales, importantes recubrimientos de vegetación, aunque no lo suficiente como para contrarrestar el efecto de la erosión. En ladera de exposición Oeste es posible encontrar los primeros indicios de arrastre de materiales producto del lavado del suelo. Se mantiene sin embargo, una creciente regeneración de especies tales como quillay, chagual, quilo, romerillo y colihue.

Un aspecto importante a considerar en el estudio de la regeneración en laderas, es la presencia de otras especies de arbustos que, no estando presentes en las parcelas evaluadas, forman parte de la cobertura vegetal joven después de incendio. Es el caso del colliguay (Colliguaja odorifera (Mol.)), dispuesta en prácticamente todas las laderas evaluadas y el corontillo (Escallonia pulverulenta (Ruiz et Pav.) Pers.), especie dispuesta preferentemente en fondos de quebradas.

El cambio en el paisaje vegetal se vuelve evidente a veintiún meses del incendio ocurrido en febrero de 2004. Sin embargo, resalta la fuerza de la regeneración de las especies componentes del matorral abierto en un estado degradado, y la proliferación y cubrimiento absoluto del suelo por malezas y una densa maraña de colihues. Otras especies como la zarzamora surge en las partes bajas de quebradas, entremezclados con los renuevos de matorral esclerófilo.

Estos comentarios surgen de la tercera medición de campo, efectuada en el mes de noviembre de 2005, cuyos resultados se presentan en la tabla 3.

Los antecedentes señalados en dicha tabla, permiten inferir una rápida recuperación de aquellos espacios descubiertos a pocos meses del incendio, generando formas caprichosas en el suelo (figura 8), que luego fueron poblándose 

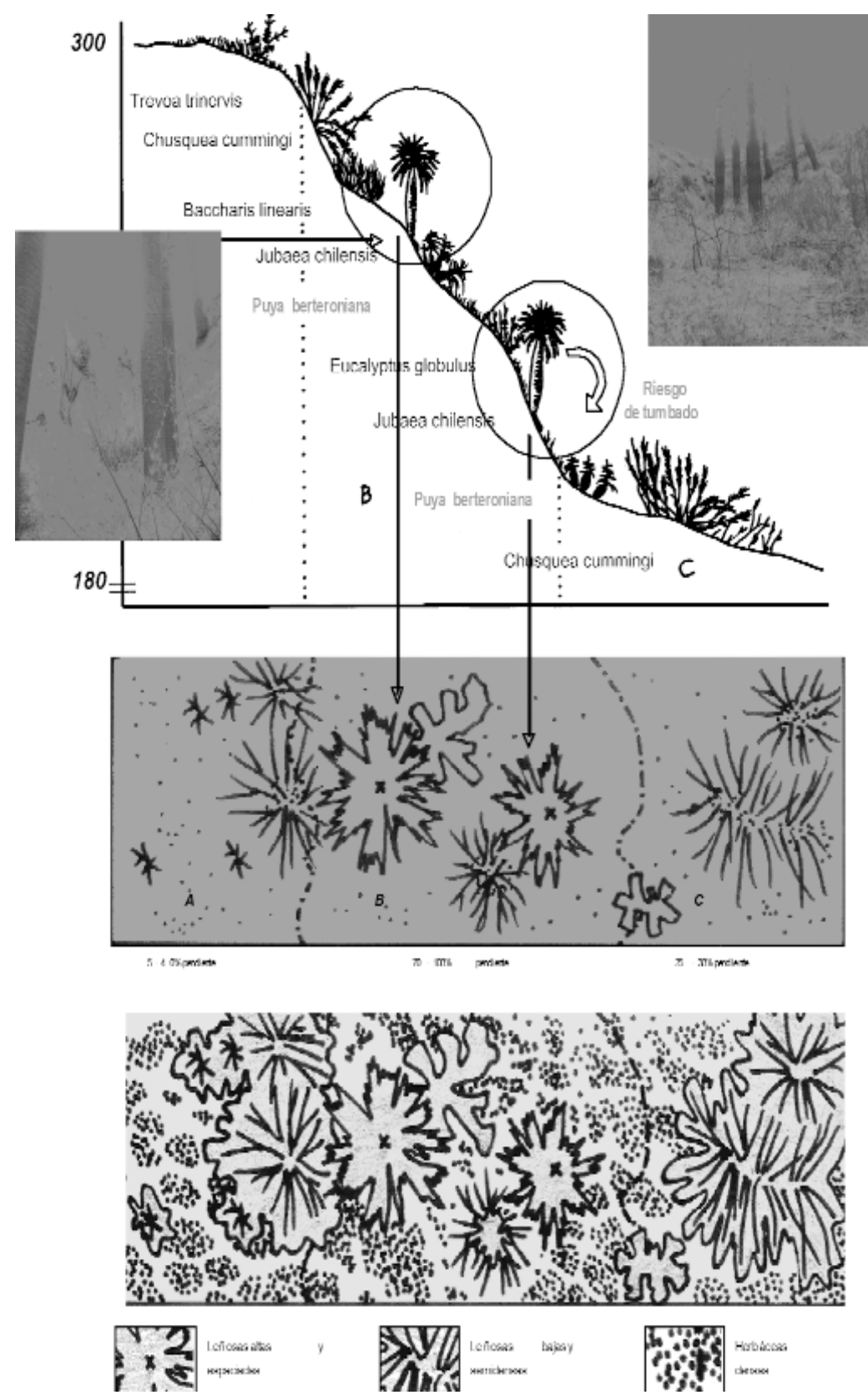

Figura 7. Ilustración del recubrimiento horizontal y vertical de vegetación producto de un seguimiento de 21 meses en la acción del fuego. 
de vegetación, conteniendo parcialmente la acción de la erosión. Un denso estrato de colihues y zarzamoras cubre ampliamente las partes medias y bajas de laderas, compitiendo fuertemente por luz y nutrientes con los retoños de vegetación arbórea del matorral esclerófilo.

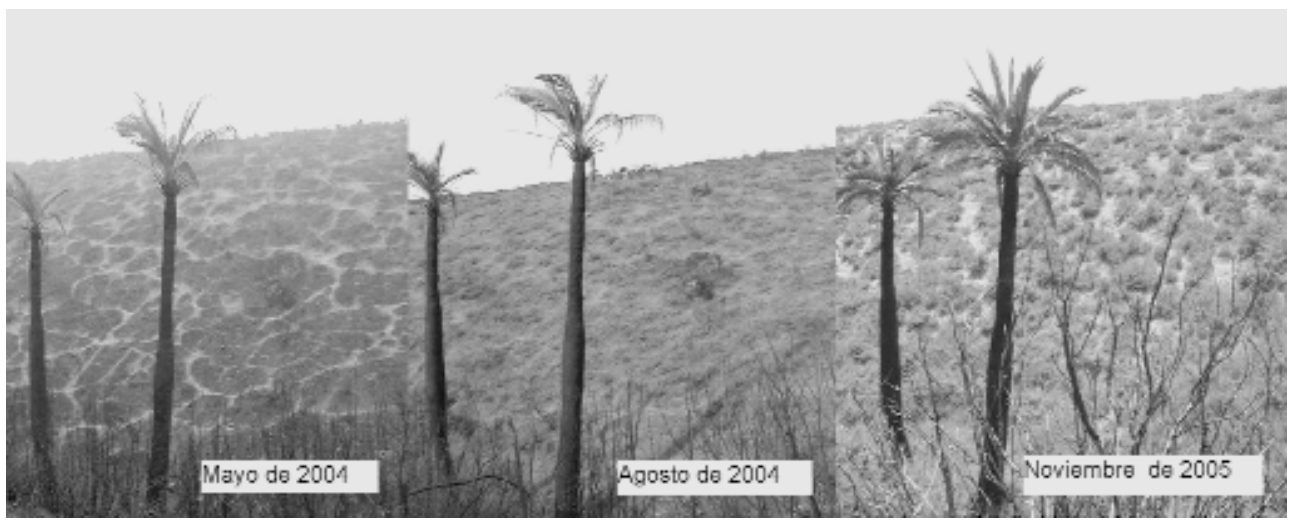

Figura 8. El paso reiterado del fuego sobre laderas degradadas genera finalmente el despoblamiento total del suelo a cenizas, generándose caprichosas formas que luego son recubiertas de vegetación herbácea. Fotos: ladera de exposición Oeste, en un seguimiento a tres, seis y veintiún meses de la acción del fuego.

En la figura anterior, no sólo se advierte la proliferación de matorral, sino también el crecimiento de nuevas hojas de las palmas. Un follaje nuevo reemplaza a los restos calcinados por el fuego, dando paso a la posibilidad de ser nuevamente utilizadas para actividades extractivas (sus hojas y frutos), principalmente en épocas de festividades.

Respecto al grado de intensidad del fuego, usualmente se determina por la velocidad de recuperación de la vegetación y por el grado de afectación en el suelo. En términos locales, incendios de las características del área afectada se caracterizan por una rápida propagación en superficie y con intensidades calóricas que fluctúan entre 500 y $1.500 \mathrm{Kcal} / \mathrm{m} / \mathrm{seg}$, dependiendo de las condiciones ambientales y topográficas de propagación (SEVEIF, 2010). Los resultados obtenidos en el seguimiento de 21 meses postfuego, indican la presencia de puntos críticos de afectación debido a la alta intensidad del fuego, en pendientes elevadas y la presencia de quebradas profundas.

Se aprecia un problema de la inestabilidad mecánica del suelo y posibilidades de tumbado, y la nula posibilidad de regeneración natural por la constante extracción de 
semilla comestible (drupas o coquitos) en épocas de floración (meses de junio y julio), que ocasiona que esta especie no tenga mayores posibilidades de generar poblaciones juveniles en estas condiciones. Los efectos de la erosión son más evidentes en las secciones medias de los perfiles, con pendientes cercanas al 70\%. La respuesta de la regeneración en laderas es bastante representativa en condiciones equivalentes a otros cerros aledaños. En las partes bajas coexiste el matorral degradado en regeneración entremezclado con chaguales y colihues. En general, no sólo se advierte la proliferación de matorral, sino también el crecimiento de nuevas hojas de las palmas.

La acción reiterada del fuego también ocasiona importantes daños a la corteza de esta especie, que si bien está adaptada a incendios moderados, no tiene la capacidad de recuperación de material leñoso de protección, debido a la reiteración e intensidad calórica alcanzada por la acción prolongada de las llamas en episodios de fuego (figuras 9 y 10). Esto, junto al problema de la inestabilidad mecánica del suelo y posibilidades de tumbado, y la nula posibilidad de regeneración natural por la constante extracción de semilla comestible (drupas o coquitos) en épocas de floración (meses de junio y julio), ocasiona que esta especie no tenga mayores posibilidades de generar poblaciones juveniles, en estas condiciones.

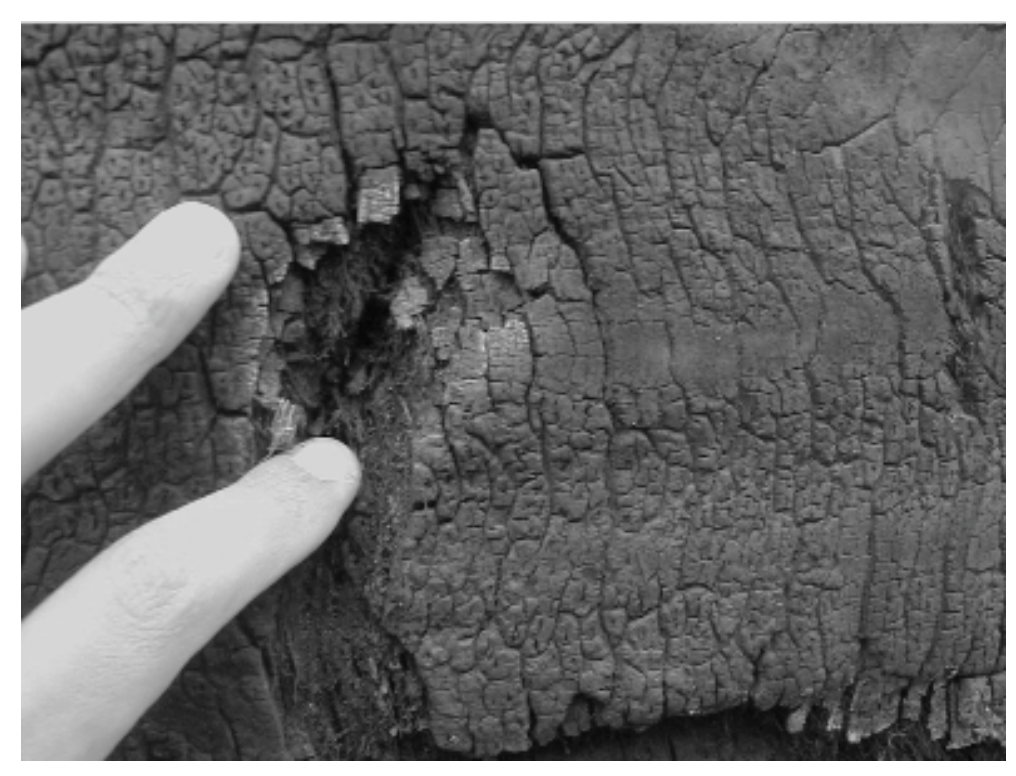

Figura 9. Corteza de palma calcinada hasta $30 \mathrm{~mm}$ de espesor. 


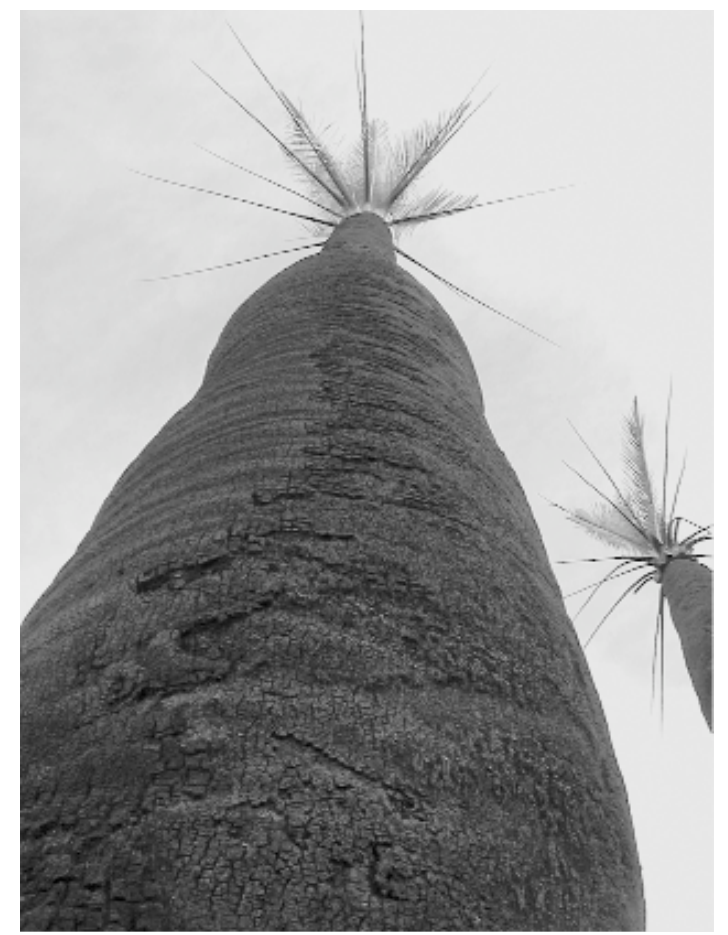

Figura 10. Vista panorámica de un ejemplar adulto de 14 metros de altura, en fondo de quebrada.

La ladera de exposición norte fue una de las más interesantes de analizar por la gran cantidad de ejemplares de palma presentes. En la parcela realizada se contabilizaron 11 ejemplares adultos; sin embargo, a lo largo de toda la exposición del cerro este número supera los 80 .

Se advierte una rápida recuperación del follaje aéreo de palmas, junto a un rápido recubrimiento de vegetación densa al interior de los espacios ocupados por esta especie. Estas condiciones permiten otorgar al suelo una mayor estabilidad y, al mismo tiempo, crea una cobertura de protección para el crecimiento de hierbas menores.

A escala local, los resultados de las existencias de palma chilena en quebradas locales y cerros aledaños muestran poblaciones adultas muy dispersas en una extensa área, conformada por las quebradas de la Hacienda Siete Hermanas y cerros colindantes a poblaciones del sector sur de Viña del Mar. 
Es posible apreciar la incidencia del efecto borde por los escasos agrupamientos de palmas adultas, producto de la acción del fuego que desprotege constantemente la vegetación acompañante que sirve de abrigo y sostén mecánico al suelo en donde se desarrollan.

Este fenómeno es particularmente notable al revisar las poblaciones adultas de palmas quemadas en extensos sectores de las Quebradas de El Salto y Hacienda Siete Hermanas. Los reiterados fuegos y la facilidad de acceso a lugares donde se desarrolla esta especie, hace casi imposible la posibilidad de regeneración por semillas.

En los transectos analizados, pudo observarse la ausencia total de poblaciones jóvenes, quedando reducida la presencia a ejemplares adultos dispuestos en sectores de altas pendientes. Por lo anterior, la dinámica poblacional de esta especie queda interrumpida en la fase de adultez. Sin considerar las existencias de palma para fines de producción por parte de privados, y las presentes en las áreas de protección, la especie se encamina a una inminente desaparición en aquellos sectores donde no es protegida. Los resultados derivados de esta investigación a escala local, y en el incendio analizado, son totalmente comparables a extensas áreas vecinas en donde las condiciones de degradación de esta especie son similares a las encontradas en el área local de estudio.

\section{Conclusiones}

Los resultados reportados en este estudio, ratifican los antecedentes de González (1998), quien analizó la estructura de la población de palma chilena existente en la Hacienda Siete Hermanas, con el propósito de determinar los factores más relevantes que han originado la disminución de la población de la especie y el proceso de fragmentación que lo afecta. Mediante la identificación de 10 sectores conformados por pequeñas cuencas y con la ayuda de técnicas de fotointerpretación e imágenes satelitales, se determinó que la población de palmas existentes en estos sectores se encuentra en un avanzado estado de desmoronamiento, presentando una estructura donde el $92,7 \%$ es una población adulta y un 7,3\% corresponde a población juvenil e infantil, siendo ésta última categoría prácticamente insignificante respecto a la existencia total de palmas.

Este estudio ratifica también el diagnóstico de la fragmentación sostenida de estos ecosistemas y el evidente envejecimiento de la población natural, fenómeno producido fundamentalmente por la fuerte presión antrópica especialmente en los últimos 25 años. Actualmente, la opción de regeneración natural de esta especie es prácticamente nula. En muchos sectores es posible ver cómo, dramáticamente, 
muchos ejemplares adultos están condenados a morir en un lapso breve de tiempo, debido a la multiplicidad de factores que atentan contra su regeneración natural.

Las poblaciones adultas de palma chilena encontradas en el área local de estudio se encuentran confinadas en sectores de altas pendientes y en evidente estado de degradación. La desprotección y desestabilización del suelo contribuyen en gran medida al riesgo de tumbado de ejemplares adultos. Estos procesos son favorecidos por la entrada de personas al lugar para la recolección de leña, tierra de hoja en algunos sectores, y hojas de palma. Este estado de degradación se repite en otros paisajes aledaños, especialmente en sectores de El Salto y en extensas áreas colindantes a la Ruta Las Palmas.

\section{Bibliografía}

Cardille, J; Ventura, S.; Turner, M. (2001) Environmental and social factors influencing wildfires in the Upper Midwest, USA. Ecological Applications, 11, 111-127.

Castillo, M. (2006): El cambio del paisaje vegetal afectado por incendios en la Zona Mediterránea Costera de la Quinta Región de Chile. Tesis Magíster en Geografía. Universidad de Chile, $155 \mathrm{p}$.

Chadwick, O.; Bruce, C. (1997): Forest Stand Dynamics. Mc.Graw-Hill, Inc. 470p. Wayne M. Getz Series Editor. University of California, Berkeley.

Daigle, P. (1996): Fire in the Dry Interior Forests of British Columbia. Extension Notes. №8, November 1996. Ministry of Forests Research Program. 5p.

Fulé, P.; Crouse, J.; Heinlein, T.; Moore, M.; Covington, W.; Verkamp, G. (2003): Mixed-severity fire regime in a highelevation forest of Grand Canyon, Arizona, USA. Landscape Ecology, 18: 465486. Kluwer Academic Publishers.

Fuller, D. (2001): Forest fragmentation in Loudon Country, Virginia (USA), evaluated with multitemporal Landsat imagery.
Research article. Landscape Ecology 16 627-642. Kluwer Academic Publishers.

Gergel, S.; Turner, M. (2002): Learning Landscape Ecology: A practical Guide to Concepts and Techniques. Book Reviews. Landscape Ecology 17: 91-93. Kluwer Academic Publishers.

González L. (1998): El cultivo de la Palma Chilena en el secano costero y el secano interior. Una iniciativa en marcha. Actas del Primer Congreso Latinoamericano IUFRO Valdivia, Chile.

SEVEIF (2010): Aplicación y adaptación del modelo SEVEIF para la evaluación socioeconómica del impacto de incendios forestales en la Provincia de Valparaíso, Chile. Agencia Española de Cooperación Internacional para el Desarrollo (AECID). $51 \mathrm{p}$.

Quintanilla, V. (1998): Los incendios de vegetación en el Cordón Costero de Chile Central. El apoyo de la cartografía para su gestión en la prevención y análisis. Caso de estudio. En: Contribuciones científicas y tecnológicas. Universidad de Santiago de Chile. Área Ingeniería y Tecnología. Año XXVI. №120. 27p. 
Tabla 1. Esquema utilizado para la medición de la información de campo. Los recuadros en líneas gruesas indican las parcelas realizadas, cada una evaluando los dos estratos (12 × 2). Los números indican la secuencia de mediciones efectuadas para todas las parcelas.

\begin{tabular}{|c|c|c|c|c|c|c|c|c|}
\hline \multicolumn{3}{|c|}{ Parcelas de $40 \mathrm{~m}^{2}$ realizadas } & \multicolumn{3}{|c|}{ Estrato arbóreo } & \multicolumn{3}{|c|}{ Estrato herbáceo y arbustivo } \\
\hline $\begin{array}{c}\text { Transecto } \\
N . \stackrel{o}{ }\end{array}$ & Exposición & $\begin{array}{c}\text { Sección } \\
(*)\end{array}$ & $\begin{array}{c}3 \text { meses } \\
\text { (mayo } \\
2004)\end{array}$ & $\begin{array}{c}6 \text { meses } \\
\text { (agosto } \\
2004)\end{array}$ & $\begin{array}{c}21 \text { meses } \\
\text { (nov. } \\
2005)\end{array}$ & $\begin{array}{c}3 \text { meses } \\
\text { (mayo } \\
2004)\end{array}$ & $\begin{array}{c}6 \text { meses } \\
\text { (agosto } \\
2004)\end{array}$ & $\begin{array}{c}21 \text { meses } \\
\text { (nov. } \\
2005)\end{array}$ \\
\hline 1 & OESTE & $\begin{array}{l}\text { A } \\
\text { B } \\
\text { C }\end{array}$ & $\begin{array}{l}1 \\
2 \\
3\end{array}$ & $\begin{array}{l}25 \\
26 \\
27\end{array}$ & $\begin{array}{l}49 \\
50 \\
51\end{array}$ & $\begin{array}{l}13 \\
14 \\
15\end{array}$ & $\begin{array}{l}37 \\
38 \\
39 \\
\end{array}$ & $\begin{array}{l}61 \\
62 \\
63 \\
\end{array}$ \\
\hline 2 & ESTE & $\begin{array}{l}\text { A } \\
\text { B } \\
\text { C }\end{array}$ & $\begin{array}{l}4 \\
5 \\
6\end{array}$ & $\begin{array}{l}28 \\
29 \\
30\end{array}$ & $\begin{array}{l}52 \\
53 \\
54\end{array}$ & $\begin{array}{l}16 \\
17 \\
18\end{array}$ & $\begin{array}{l}40 \\
41 \\
42\end{array}$ & $\begin{array}{l}64 \\
65 \\
66\end{array}$ \\
\hline 3 & NORTE & $\begin{array}{l}\text { A } \\
\text { B } \\
\text { C }\end{array}$ & $\begin{array}{l}7 \\
8 \\
9\end{array}$ & $\begin{array}{l}31 \\
32 \\
33\end{array}$ & $\begin{array}{l}55 \\
56 \\
57\end{array}$ & $\begin{array}{l}19 \\
20 \\
21\end{array}$ & $\begin{array}{l}43 \\
44 \\
45\end{array}$ & $\begin{array}{l}67 \\
68 \\
69\end{array}$ \\
\hline 4 & SUR & $\begin{array}{l}\text { A } \\
\text { B } \\
\text { C }\end{array}$ & $\begin{array}{l}10 \\
11 \\
12\end{array}$ & $\begin{array}{l}34 \\
35 \\
36\end{array}$ & $\begin{array}{l}58 \\
59 \\
60\end{array}$ & $\begin{array}{l}22 \\
23 \\
24\end{array}$ & $\begin{array}{l}46 \\
47 \\
48\end{array}$ & $\begin{array}{l}70 \\
71 \\
72\end{array}$ \\
\hline
\end{tabular}

(*) Secciones confeccionadas según lo detallado en diagramas. A = Sección superior ladera; B = Media ladera; C = Fondo de ladera. 
Tabla 2. Valores de presencia, altura de ejemplares (**) y cobertura (en paréntesis y porcentajes) de plantas más constantes en muestras de terreno (transectos lineales de 50 metros, parcelas de $40 \mathrm{~m}^{2}$ ), a seis meses después del fuego (agosto de 2004).

\begin{tabular}{|c|c|c|c|c|c|c|c|c|c|c|c|c|}
\hline Transecto & \multicolumn{3}{|c|}{1} & \multicolumn{3}{|c|}{2} & \multicolumn{3}{|c|}{3} & \multicolumn{3}{|c|}{4} \\
\hline Sección & $\mathrm{A}$ & $\mathrm{B}$ & $\mathrm{C}$ & $\mathrm{A}$ & $\mathrm{B}$ & $\mathrm{C}$ & A & $\mathrm{B}$ & $\mathrm{C}$ & $\mathrm{A}$ & $\mathrm{B}$ & $\mathrm{C}$ \\
\hline $\begin{array}{c}\text { Altitud (m.s.n.m) } \\
\text { Pendiente (\%) } \\
\text { Exposición }\end{array}$ & $\begin{array}{c}260 \\
10 \\
W\end{array}$ & $\begin{array}{c}220 \\
60 \\
\text { SW }\end{array}$ & $\begin{array}{c}175 \\
35 \\
W\end{array}$ & $\begin{array}{c}320 \\
70 \\
\mathrm{NE}\end{array}$ & $\begin{array}{c}210 \\
45 \\
E\end{array}$ & $\begin{array}{c}160 \\
25 \\
\mathrm{E}\end{array}$ & $\begin{array}{c}300 \\
10 \\
\mathrm{NE}\end{array}$ & $\begin{array}{c}245 \\
65 \\
\mathrm{NE}\end{array}$ & $\begin{array}{c}195 \\
20 \\
\mathrm{~N}\end{array}$ & $\begin{array}{c}320 \\
12 \\
\mathrm{~S}\end{array}$ & $\begin{array}{c}265 \\
40 \\
S\end{array}$ & $\begin{array}{c}225 \\
25 \\
S\end{array}$ \\
\hline \multicolumn{13}{|l|}{ Estrato arbóreo } \\
\hline $\begin{array}{l}\text { palma chilena } \\
\text { (Jubaea chilensis) }\end{array}$ & - & - & - & $\begin{array}{c}7,14 \\
(5)\end{array}$ & - & - & - & $\begin{array}{l}11,16 \\
(5)\end{array}$ & - & - & - & - \\
\hline $\begin{array}{c}\text { quillay } \\
\text { (Quilaja saponaria) }\end{array}$ & $\begin{array}{ll}4, & 0.7 \\
(10)\end{array}$ & - & - & - & - & - & - & - & - & $\begin{array}{cc}9, & 0.8 \\
(30)\end{array}$ & $\begin{array}{cc}2, & 0.5 \\
(7)\end{array}$ & - \\
\hline $\begin{array}{c}\text { litre } \\
\text { (Lithraea caustica) }\end{array}$ & - & - & - & - & $\begin{array}{c}7,0.4 \\
(15)\end{array}$ & - & - & - & - & - & $\begin{array}{cc}4,0.3 \\
(15)\end{array}$ & - \\
\hline $\begin{array}{c}\text { boldo } \\
\text { (Peumus boldus) }\end{array}$ & - & - & - & - & - & - & - & - & - & - & - & $\begin{array}{cc}4, & 0.3 \\
(20)\end{array}$ \\
\hline $\begin{array}{c}\text { eucalipto } \\
\text { (Eucalyptus globulus) }\end{array}$ & - & $\begin{array}{cc}7, & 0.6 \\
(6)\end{array}$ & - & $\begin{array}{c}12,0.5 \\
(5)\end{array}$ & - & - & - & $\begin{array}{ll}1, & 0.7 \\
(<1)\end{array}$ & - & - & - & - \\
\hline $\begin{array}{c}\text { chagual } \\
\text { (Puya berteroniana) }\end{array}$ & - & $\begin{array}{c}3,0.8 \\
(5)\end{array}$ & $\begin{array}{cc}5, & 0.5 \\
(15)\end{array}$ & $\begin{array}{cc}3, & 0.5 \\
(5)\end{array}$ & $\begin{array}{l}1,1.2 \\
(<1)\end{array}$ & - & - & $\begin{array}{l}1,1.5 \\
(<1)\end{array}$ & $\begin{array}{cc}1, & 0.5 \\
(<1)\end{array}$ & - & - & - \\
\hline $\begin{array}{c}\text { Total cobertura } \\
\text { estrato arbóreo (renuevos) }\end{array}$ & (10) & (11) & (15) & (15) & (15) & (0) & (0) & (5) & (0) & (30) & (22) & (20) \\
\hline \multicolumn{13}{|l|}{ Estrato arbustivo y herbáceo } \\
\hline $\begin{array}{c}\text { colihue } \\
\text { (Chusquea cumingil) }\end{array}$ & - & $\begin{array}{c}11 \\
1.8 \\
(12)\end{array}$ & $\begin{array}{c}8,0.7 \\
(30)\end{array}$ & $\begin{array}{l}4,1 \\
(10)\end{array}$ & $\begin{array}{cc}4, & 0.9 \\
(15)\end{array}$ & $\begin{array}{r}7,1.5 \\
(30)\end{array}$ & $\begin{array}{c}2,1.7 \\
(5)\end{array}$ & $\begin{array}{cc}3, & 0.8 \\
(2)\end{array}$ & $\begin{array}{l}8,1 \\
(10)\end{array}$ & - & $\begin{array}{cc}2, & 1.2 \\
(5)\end{array}$ & $\begin{array}{c}9,1.5 \\
(10)\end{array}$ \\
\hline $\begin{array}{c}\text { romerillo } \\
\text { (Baccharis linearis) }\end{array}$ & {$\left[\begin{array}{ll}5, & 0.2 \\
(3)\end{array}\right.$} & - & - & $\begin{array}{cc}2, & 0.2 \\
(<1)\end{array}$ & - & - & - & $\begin{array}{cc}3, & 0.4 \\
(<1)\end{array}$ & - & - & \begin{tabular}{c|}
1 \\
0.15 \\
$(<1)$
\end{tabular} & - \\
\hline $\begin{array}{c}\text { trevo } \\
\text { (Trevoa trinervis) }\end{array}$ & - & $\begin{array}{cc}1, & 0.4 \\
(<1)\end{array}$ & - & - & - & - & $\begin{array}{cc}2, & 0.3 \\
(<1)\end{array}$ & - & - & - & $\begin{array}{cc}1, & 0.7 \\
(<1)\end{array}$ & - \\
\hline $\begin{array}{c}\text { quilo } \\
\text { (Mueblenbeckia hastulata) }\end{array}$ & - & $\begin{array}{cc}2, & 0.2 \\
(<1)\end{array}$ & - & - & - & - & - & - & - & - & - & - \\
\hline $\begin{array}{l}\text { Hierbas menores } \\
\text { (manto vegeta) }\end{array}$ & $(50)$ & $(55)$ & (45) & (40) & $(60)$ & (55) & $(55)$ & $(45)$ & $(50)$ & $(45)$ & $(50)$ & (40) \\
\hline $\begin{array}{l}\text { Total cobertura estrato } \\
\text { herbáceo y arbustivo }\end{array}$ & (53) & $(\approx 69)$ & (75) & $(\approx 51)$ & (75) & (0) & $(\approx 61)$ & $(\approx 48)$ & (60) & (45) & $(\approx 57)$ & (50) \\
\hline
\end{tabular}

${ }^{* *}$ La altura medida corresponde a los renuevos de vegetación medidos a partir de la superficie del suelo. No considera la altura de la estructura leñosa quemada. En el caso del chagual, sólo se evaluó el seguimiento de la cobertura. 
Tabla 3. Valores de presencia, altura de ejemplares y cobertura (en paréntesis y porcentajes) de plantas más constantes en muestras de terreno (transectos lineales de 50 metros, parcelas de 40 $\mathrm{m}^{2}$ ), a veintiún meses después del fuego (noviembre de 2005).

\begin{tabular}{|c|c|c|c|c|c|c|c|c|c|c|c|c|}
\hline Transecto & \multicolumn{3}{|c|}{1} & \multicolumn{3}{|c|}{2} & \multicolumn{3}{|c|}{3} & \multicolumn{3}{|c|}{4} \\
\hline Sección & A & $\mathrm{B}$ & $\mathrm{C}$ & A & B & $\mathrm{C}$ & A & B & $\mathrm{C}$ & $\mathrm{A}$ & B & $\mathrm{C}$ \\
\hline $\begin{array}{c}\text { Altitud (m.s.n.m) } \\
\text { Pendiente (\%) } \\
\text { Exposición }\end{array}$ & $\begin{array}{c}260 \\
10 \\
W\end{array}$ & $\begin{array}{c}220 \\
60 \\
\text { SW }\end{array}$ & $\begin{array}{l}175 \\
35 \\
W\end{array}$ & $\begin{array}{c}320 \\
70 \\
\mathrm{NE}\end{array}$ & $\begin{array}{c}210 \\
45 \\
E\end{array}$ & $\begin{array}{c}160 \\
25 \\
E\end{array}$ & $\begin{array}{c}300 \\
10 \\
\mathrm{NE}\end{array}$ & $\begin{array}{l}245 \\
65 \\
\mathrm{NE}\end{array}$ & $\begin{array}{c}195 \\
20 \\
\mathrm{~N}\end{array}$ & $\begin{array}{c}320 \\
12 \\
\mathrm{~S}\end{array}$ & $\begin{array}{c}265 \\
40 \\
S\end{array}$ & $\begin{array}{c}225 \\
25 \\
S\end{array}$ \\
\hline \multicolumn{13}{|l|}{ Estrato arbóreo } \\
\hline $\begin{array}{l}\text { palma chilena } \\
\text { (Jubaea chilensis) }\end{array}$ & - & - & - & $\begin{array}{c}7,14 \\
(5)\end{array}$ & - & - & - & $\begin{array}{c}11,16 \\
(5)\end{array}$ & - & - & - & - \\
\hline $\begin{array}{c}\text { quillay } \\
\text { (Quilaja saponaria) }\end{array}$ & $\begin{array}{cc}4, & 0.7 \\
(20)\end{array}$ & - & - & - & - & - & - & - & - & $\begin{array}{c}9,1.9 \\
(35)\end{array}$ & $\begin{array}{c}2,1.6 \\
(15)\end{array}$ & - \\
\hline $\begin{array}{c}\text { litre } \\
\text { (Lithraea caustica) }\end{array}$ & - & - & - & - & $\begin{array}{cc}7,1.8 \\
(25)\end{array}$ & - & - & - & - & - & \begin{tabular}{|c|}
,$\quad 1.2$ \\
$(20)$
\end{tabular} & - \\
\hline $\begin{array}{c}\text { boldo } \\
\text { (Peumus boldus) }\end{array}$ & - & - & - & - & - & - & - & - & - & - & - & $\begin{array}{ll}4, & 0.5 \\
(20)\end{array}$ \\
\hline $\begin{array}{c}\text { eucalipto } \\
\text { (Eucalyptus globulus) }\end{array}$ & - & $\begin{array}{c}7,2.1 \\
(15)\end{array}$ & - & $\begin{array}{c}12,1.9 \\
(15)\end{array}$ & - & - & - & $\begin{array}{cc}1, & 1.5 \\
(10)\end{array}$ & - & - & - & - \\
\hline $\begin{array}{c}\text { chagual } \\
\text { (Puya berteroniana) }\end{array}$ & - & $\begin{array}{cc}3, & 0.8 \\
(10)\end{array}$ & $\begin{array}{cc}5, & 0.5 \\
(15)\end{array}$ & $\begin{array}{c}3,0.5 \\
(10)\end{array}$ & $\begin{array}{c}1,1.2 \\
(10)\end{array}$ & - & - & $\begin{array}{cc}1, & 1.5 \\
(10)\end{array}$ & $\begin{array}{cc}1, & 0.5 \\
(10)\end{array}$ & - & - & - \\
\hline $\begin{array}{c}\text { Total cobertura } \\
\text { estrato arbóreo (renuevos) }\end{array}$ & (20) & (25) & (15) & (30) & (35) & (0) & (0) & (25) & (10) & (35) & (35) & (20) \\
\hline \multicolumn{13}{|l|}{ Estrato arbustivo y herbáceo } \\
\hline $\begin{array}{c}\text { colihue } \\
\text { (Chusquea cumingil) }\end{array}$ & - & $\begin{array}{c}11 \\
3 \\
(20)\end{array}$ & $\begin{array}{c}8,2.8 \\
(35)\end{array}$ & $\begin{array}{l}4,3 \\
(15)\end{array}$ & $\begin{array}{c}4,3.5 \\
(20)\end{array}$ & $\begin{array}{c}7,2.5 \\
(30)\end{array}$ & $\begin{array}{l}2,3 \\
(10)\end{array}$ & $\begin{array}{l}3,3 \\
(10)\end{array}$ & $\begin{array}{l}8,3 \\
(20)\end{array}$ & - & $\begin{array}{l}2,3 \\
(20)\end{array}$ & $\begin{array}{l}9,3 \\
(20)\end{array}$ \\
\hline $\begin{array}{l}\text { romerillo } \\
\text { (Baccharis linearis) }\end{array}$ & $\begin{array}{c}5,0.1 \\
(5)\end{array}$ & - & - & $\begin{array}{cc}2, & 1 \\
(2)\end{array}$ & - & - & - & $\begin{array}{cc}3, & 1.2 \\
(2)\end{array}$ & - & - & $\begin{array}{l}1 \\
0.5 \\
(3)\end{array}$ & - \\
\hline $\begin{array}{c}\text { trevo } \\
\text { (Trevoa trinervis) }\end{array}$ & - & $\begin{array}{c}1,1 \\
(5)\end{array}$ & - & - & - & - & $\begin{array}{c}2,0.8 \\
(2)\end{array}$ & - & - & - & $\begin{array}{cc}1, & 0.7 \\
(<1)\end{array}$ & - \\
\hline $\begin{array}{c}\text { quilo } \\
\text { (Mueblenbeckia hastulata) }\end{array}$ & - & $\begin{array}{cc}2, & 0.2 \\
(2)\end{array}$ & - & - & - & - & - & - & - & - & - & - \\
\hline $\begin{array}{l}\text { Hierbas menores } \\
\text { (manto vegeta) }\end{array}$ & (55) & $(55)$ & (45) & (45) & (55) & $(60)$ & $(60)$ & (45) & $(55)$ & $(45)$ & (50) & $(40)$ \\
\hline $\begin{array}{l}\text { Total cobertura estrato } \\
\text { herbáceo y arbustivo }\end{array}$ & (60) & (82) & (80) & (62) & (75) & (90) & (72) & (57) & (75) & (45) & $(\approx 74)$ & (60) \\
\hline
\end{tabular}

${ }^{(* *}$ La altura medida corresponde a los renuevos de vegetación medidos a partir de la superficie del suelo. No considera la altura de la estructura leñosa quemada. En el caso del chagual, sólo se evaluó el seguimiento de la cobertura. 